Article

\title{
The Role of Enterococcus faecium as a Key Producer and Fermentation Condition as an Influencing Factor in Tyramine Accumulation in Cheonggukjang
}

\author{
Young Kyoung Park ${ }^{1}$, Young Hun Jin ${ }^{1}{ }^{\circledR}$, Jun-Hee Lee ${ }^{1}$, Bo Young Byun ${ }^{1}$, Junsu Lee ${ }^{1}$, \\ KwangCheol Casey Jeong ${ }^{2,3}$ and Jae-Hyung Mah ${ }^{1, *(1)}$ \\ 1 Department of Food and Biotechnology, Korea University, 2511 Sejong-ro, Sejong 30019, Korea; \\ eskimo@korea.ac.kr (Y.K.P.); younghoonjin3090@korea.ac.kr (Y.H.J.); bory92@korea.ac.kr (J.-H.L.); \\ by-love23@hanmail.net (B.Y.B.); jpang@korea.ac.kr (J.L.) \\ 2 Department of Animal Sciences, University of Florida, Gainesville, FL 32611, USA; kcjeong@ufl.edu \\ 3 Emerging Pathogens Institute, University of Florida, Gainesville, FL 32611, USA \\ * Correspondence: nextbio@korea.ac.kr; Tel.: +82-44-860-1431
}

Received: 10 June 2020; Accepted: 8 July 2020; Published: 11 July 2020

\begin{abstract}
The study evaluated the role of Enterococcus faecium in tyramine production and its response to fermentation temperature in a traditional Korean fermented soybean paste, Cheonggukjang. Tyramine content was detected in retail Cheonggukjang products at high concentrations exceeding the recommended limit up to a factor of 14 . All retail Cheonggukjang products contained Enterococcus spp. at concentrations of at least $6 \mathrm{Log}$ CFU/g. Upon isolation of Enterococcus strains, approximately 93\% (157 strains) produced tyramine at over $100 \mu \mathrm{g} / \mathrm{mL}$. The strains that produced the highest concentrations of tyramine $(301.14-315.29 \mu \mathrm{g} / \mathrm{mL})$ were identified as E. faecium through $16 \mathrm{~S}$ rRNA sequencing. The results indicate that E. faecium is one of the major contributing factors to high tyramine content in Cheonggukjang. During fermentation, tyramine content in Cheonggukjang groups co-inoculated with E. faecium strains was highest at $45^{\circ} \mathrm{C}$, followed by $37^{\circ} \mathrm{C}$ and $25^{\circ} \mathrm{C}$. The tyramine content of most Cheonggukjang groups continually increased as fermentation progressed, except groups fermented at $25^{\circ} \mathrm{C}$. At $45^{\circ} \mathrm{C}$, the tyramine content occasionally exceeded the recommended limit within 3 days of fermentation. The results suggest that lowering fermentation temperature and shortening duration may reduce the tyramine content of Cheonggukjang, thereby reducing the safety risks that may arise when consuming food with high tyramine concentrations.
\end{abstract}

Keywords: Cheonggukjang; Enterococcus faecium; tyramine; biogenic amines; fermentation temperature; fermentation duration; tyrosine decarboxylase gene $(t d c)$

\section{Introduction}

Cheonggukjang is a traditional Korean soybean paste produced by fermenting soybeans with Bacillus subtilis. Traditional methods of Cheonggukjang production utilize rice straw added to steamed soybeans for a short fermentation period of approximately 2-3 days, while starter cultures are used instead of rice straw for modern methods of production [1,2]. Fermentation of Cheonggukjang is a process involving microbial enzymatic proteolysis resulting in uniquely characteristic savory aromatic and flavor properties [3]. Consumption of Cheonggukjang has been reported to be associated with numerous benefits such as antioxidative, antihypertensive, thrombolytic, and antimicrobial properties $[4,5]$. However, despite the beneficial properties of Cheonggukjang, potentially hazardous biogenic amines (BAs) may be produced during fermentation of the proteinous food rich in precursor amino acids.

The majority of BAs are formed through the reductive amination of ketones and aldehydes, as well as the decarboxylation of amino acids by microbially produced enzymes [6]. Though BAs are 
essential for the regulation of protein synthesis, nucleic acid functions, and membrane stabilization in living cells, consumption of food products with high concentrations of BAs may result in toxicological effects [7-10]. The excessive intake of food products such as mackerel, pacific saury, sardines, and tuna may result in "scombroid poisoning" owing to potentially high concentrations of toxic histamine that may cause symptoms similar to an allergic reaction including diarrhea, dyspnea, headache, hives, and hypotension [10-13]. Overconsumption of foods with high concentrations of tyramine may potentially result in a "cheese crisis" with various symptoms including heart failure, hemorrhages, hypertensive crisis, high blood pressure, and severe headaches $[9,10,14,15]$. Such a high content of tyramine produced by microbial tyrosine decarboxylase activity has occasionally been found in tyrosine-rich foods such as cheese [16,17] and soybean-based fermented products [18-20]. Therefore, Ten Brink, et al. [21] suggested BA toxicity limits of $30 \mathrm{mg} / \mathrm{kg}$ for $\beta$-phenylethylamine, $100 \mathrm{mg} / \mathrm{kg}$ for histamine, and $100-800 \mathrm{mg} / \mathrm{kg}$ for tyramine in foods.

Previous studies by Ko, et al. [18], Jeon, et al. [19], and Seo, et al. [20] on the BA content of Cheonggukjang have shown that tyramine in particular has been detected in high concentrations up to 1913.51, 251.66, and $905.0 \mathrm{mg} / \mathrm{kg}$, respectively. Ibe, et al. [22] suggested that Enterococcus faecium may be largely responsible for the BA content of Miso (a Japanese fermented soybean paste). Notably, numerous studies have reported that Enterococcus spp. possess the tyrosine decarboxylase gene $(t d c)[23,24]$. Moreover, in particular Kang and Park [25] and Kang, et al. [26] confirmed the presence of E. faecium in Cheonggukjang, while a previous study by Jeon, et al. [19] showed that Enterococcus spp. isolated from Cheonggukjang exhibited tyramine production at concentrations of at least $351.59 \mu \mathrm{g} / \mathrm{mL}$. Taken together, the previous reports imply that E. faecium may also be responsible for the BA content of Cheonggukjang. Meanwhile, the growth of Enterococcus spp. has been reported to occur at temperatures ranging from $10{ }^{\circ} \mathrm{C}$ up to $45^{\circ} \mathrm{C}$ that overlap with Cheonggukjang fermentation temperatures ranging from 25 to $50^{\circ} \mathrm{C}$ [27-30]. The corresponding range in temperature may be beneficial for E. faecium growth and tyramine production during the fermentation of contaminated Cheonggukjang products. Furthermore, a previous study reported that tyramine content increases in fermented soybeans as fermentation progresses [19]. According to Bhardwaj, et al. [31], the production of tyramine by E. faecium strains may be affected by incubation conditions such as temperature and time. Therefore, the current study assessed the safety risk of BAs (particularly tyramine) in Cheonggukjang, clarified the microorganism responsible for tyramine accumulation, and evaluated the effect of fermentation temperature/duration on E. faecium growth and subsequent tyramine production in the food.

\section{Materials and Methods}

\subsection{Cheonggukjang Products}

Six representative, but different Cheonggukjang products were purchased from various retail markets in the Republic of Korea and stored at $4{ }^{\circ} \mathrm{C}$ until further experimentation. Within a day of storage, the BA content of Cheonggukjang products was measured, followed by physicochemical and microbial analyses.

\subsection{Physicochemical Analyses}

To investigate the influencing factors such as $\mathrm{pH}$, salinity, and water activity on BA content in Cheonggukjang, the physicochemical properties of Cheonggukjang samples (retail Cheonggukjang products purchased and Cheonggukjang groups fermented in this study) were measured as described below. Samples weighing $10 \mathrm{~g}$ using an analytical balance (Ohaus Adventurer ${ }^{\mathrm{TM}}$, Ohaus Corporation, Parsippany, NJ, USA) were homogenized with $90 \mathrm{~mL}$ of distilled water using a stomacher (Laboratory Blender Stomacher 400, Seward, Ltd., Worthing, UK). The $\mathrm{pH}$ of the homogenates was measured using a $\mathrm{pH}$ meter (Orion 3-star $\mathrm{pH}$ Benchtop Thermo Scientific, Waltham, MA, USA), while salinity was measured using the procedure described by the Association of Official Analytical Chemists 
(AOAC; Official Method 960.29) [32]. The water activity of the samples was measured using an electric hygrometer (AquaLab Pre, Meter Group, Inc., Pullman, WA, USA).

\subsection{Microbial Analyses}

The analysis of the microbial community in Cheonggukjang samples was conducted using Plate Count Agar (PCA; Difco, Becton Dickinson, Sparks, MD, USA); de Man, Rogosa, and Sharpe (MRS; Conda, Madrid, Spain) agar; and m-Enterococcus Agar (m-EA; MB Cell, Seoul, Korea) for the enumeration of total mesophilic viable bacteria, lactic acid bacteria, and Enterococcus spp., respectively. Samples weighing $10 \mathrm{~g}$ were homogenized with $90 \mathrm{~mL}$ of sterile $0.1 \%$ peptone saline using a stomacher. The homogenates were 10 -fold serially diluted with $0.1 \%$ peptone saline up to $10^{-5}$, and $100 \mu \mathrm{L}$ of each dilution was spread on PCA, MRS agar, and m-EA in duplicates. Incubation conditions were set according to the manufacturer's instructions: PCA at $37^{\circ} \mathrm{C}$ for $24 \mathrm{~h}$ and m-EA at $37^{\circ} \mathrm{C}$ for $48 \mathrm{~h}$ under aerobic condition; MRS agar at $37^{\circ} \mathrm{C}$ for $48 \mathrm{~h}$ under anaerobic condition. Anaerobic condition was achieved using an anaerobic chamber (Coy Lab. Products, Inc., Grass Lake, MI, USA) containing an atmosphere of $95 \%$ nitrogen and $5 \%$ hydrogen. After incubation, the bacterial concentrations of the Cheonggukjang samples were calculated by enumerating the colony-forming units (CFU) on the plates of respective media with approximately 10 to 300 colonies [33] and adjusting for the dilution.

\subsection{Isolation and Identification of Enterococcus Strains from Retail Cheonggukjang Products}

A total of 169 Enterococcus strains were isolated from retail Cheonggukjang products according to the method described by Mareková, et al. [34], with minor modifications. Upon enumeration of colonies on m-EA, individual colonies were streaked on MRS agar and incubated at $37^{\circ} \mathrm{C}$ for $48 \mathrm{~h}$ under anaerobic condition. Single colonies were streaked again on MRS agar and incubated under the same conditions. The pure single colonies were inoculated in MRS broth, incubated at $37^{\circ} \mathrm{C}$ for $48 \mathrm{~h}$, and stored at $-70{ }^{\circ} \mathrm{C}$ using glycerol $(20 \%, v / v)$.

The identities (at species level) of the individual Enterococcus strains that displayed the highest tyramine production were further investigated through sequence analysis of $16 \mathrm{~S}$ rRNA gene amplified with the universal bacterial primer pair 518F (5'-CCAGCAGCCGCGGTAATACG-3') and 805R (5'-GACTACCAGGGTATCTAAT-3') (Solgent Co., Daejeon, Korea). The identities of sequences were determined using the basic local alignment search tool (BLAST) of the National Center for Biotechnology Information (NCBI; http://www.ncbi.nlm.nih.gov/BLAST/).

\subsection{Preparation of Cheonggukjang}

To investigate the effect of fermentation temperature on tyramine production by E. faecium, several temperatures were set for in situ Cheonggukjang fermentation experiments. The temperature for Cheonggukjang fermentation (intermediate-temperature group) was determined based upon previous studies in which $37^{\circ} \mathrm{C}$ was reported as the temperature commonly used for Cheonggukjang production $[19,35,36]$. In addition, the temperatures of $25^{\circ} \mathrm{C}$ and $45^{\circ} \mathrm{C}$ used by other studies for Cheonggukjang fermentation were utilized for the low and high temperature groups, respectively $[29,30]$.

White soybeans (Glycine max Merrill) were purchased from a retail market in the Republic of Korea. The soybeans were soaked in distilled water at $4{ }^{\circ} \mathrm{C}$ for $12 \mathrm{~h}$, and subsequently drained for $1 \mathrm{~h}$. Approximately $200 \mathrm{~g}$ of soybeans were adjusted to a final salinity of $2.40 \%$ according to the salinity of Cheonggukjang outlined in the 9th revision of the Korean food composition table [37] and subsequently steamed at $125^{\circ} \mathrm{C}$ for $30 \mathrm{~min}$ using an autoclave. The steamed soybeans were cooled to $50{ }^{\circ} \mathrm{C}$ and inoculated with bacterial inocula in $\mathrm{M} / 15$ Sörensen's phosphate buffer ( $\mathrm{pH} 7$ ) to final concentrations of approximately 6 Log CFU/g of B. subtilis KCTC 3135 (also designated as ATCC 6051; type strain) and 4 Log CFU/g of E. faecium KCCM 12118 (ATCC 19434; type strain) or E. faecium CJE 216 (strain isolated from Cheonggukjang and selected owing to both strong tyramine production and $t d c$ gene expression). The control group (without any E. faecium strains) was inoculated with only B. subtilis KCTC 3135 to a final concentration of $6 \mathrm{Log}$ CFU/g. The sizes of inocula were selected with 
consideration of the cell count of each microorganism in Cheonggukjang products determined in our previous study [19]. The inoculated steamed soybeans were then fermented at $25^{\circ} \mathrm{C}, 37^{\circ} \mathrm{C}$, or $45^{\circ} \mathrm{C}$ for 3 days. Approximately $20 \mathrm{~g}$ of the fermented soybeans were collected daily during fermentation to measure the BA content as well as physicochemical and microbial properties. Fermented soybeans sampled during fermentation were stored at $-70^{\circ} \mathrm{C}$ for further testing, as required.

\subsection{BA Analyses in Cheonggukjang Samples and Bacterial Cultures}

\subsubsection{BA Extraction from Cheonggukjang Samples and Bacterial Cultures}

Quantification of the BA content of Cheonggukjang was conducted as previously described by Ben-Gigirey, et al. [38]. Five grams of Cheonggukjang with $20 \mathrm{~mL}$ of $0.4 \mathrm{M}$ perchloric acid (Sigma-Aldrich, St. Louis, MO, USA) were homogenized by vortex (Vortex-Genie, Scientific industries, Bohemia, NY, USA) and stored at $4{ }^{\circ} \mathrm{C}$ for $2 \mathrm{~h}$. The mixture was then centrifuged at $3000 \times g$ for $10 \mathrm{~min}$ at $4{ }^{\circ} \mathrm{C}(1736 \mathrm{R}$, Labogene, Seoul, Korea), and the supernatant was collected. Upon resuspension of the pellet with $20 \mathrm{~mL}$ of $0.4 \mathrm{M}$ perchloric acid, the mixture was stored at $4{ }^{\circ} \mathrm{C}$ for $2 \mathrm{~h}$ and centrifuged again at $3000 \times g$ at $4{ }^{\circ} \mathrm{C}$ for $10 \mathrm{~min}$. The supernatant was combined with the previously collected supernatant and adjusted to a final volume of $50 \mathrm{~mL}$ with $0.4 \mathrm{M}$ perchloric acid. Then, the extract was filtered through Whatman paper No. 1 (Whatman International Ltd., Maidstone, UK).

The bacterial production of BAs was measured using the procedures described by Eerola, et al. [39], modified by Ben-Gigirey, et al. [38,40], and further modified in the present study to culture Enterococcus spp. based on Marcobal, et al. [41]. A loopful $(10 \mu \mathrm{L})$ of glycerol stock of each enterococcal strain was inoculated in $5 \mathrm{~mL}$ of MRS broth supplemented with $0.5 \%$ of each amino acid, including L-histidine monohydrochloride monohydrate, L-tyrosine disodium salt hydrate, L-ornithine monohydrochloride, L-lysine monohydrochloride ( $\mathrm{pH} 5.8$ ), and $0.0005 \%$ pyridoxal- $\mathrm{HCl}$ (all from Sigma-Aldrich) and incubated at $37^{\circ} \mathrm{C}$ for $48 \mathrm{~h}$. Approximately $100 \mu \mathrm{L}$ of the broth culture was then transferred to another tube containing $5 \mathrm{~mL}$ of the same medium. Upon incubation at $37^{\circ} \mathrm{C}$ for $48 \mathrm{~h}$, the broth culture was filtered using a sterile syringe with a $0.2 \mu \mathrm{m}$ membrane (Millipore Co., Bedford, MA, USA). Then, $9 \mathrm{~mL}$ of $0.4 \mathrm{M}$ perchloric acid were added to $1 \mathrm{~mL}$ of the filtered broth culture and mixed by a vortex mixer. The mixture was reacted in a cold chamber at $4{ }^{\circ} \mathrm{C}$ for $2 \mathrm{~h}$ and centrifuged at $3000 \times g$ at $4{ }^{\circ} \mathrm{C}$ for $10 \mathrm{~min}$. The extract was filtered through Whatman paper No. 1.

\subsubsection{Preparation of Standard Solutions for High Performance Liquid Chromatography (HPLC) Analysis}

Standard solutions with concentrations of $0,10,50,100$, and 1000 ppm were prepared for tryptamine, $\beta$-phenylethylamine hydrochloride, putrescine dihydrochloride, cadaverine dihydrochloride, histamine dihydrochloride, tyramine hydrochloride, spermidine trihydrochloride, and spermine tetrahydrochloride (all from Sigma-Aldrich). Internal standard solution with the same concentrations was prepared using 1,7-diaminoheptane (Sigma-Aldrich).

\subsubsection{Derivatization of Extracts and Standards}

Derivatization of BAs was conducted according to the method described by Eerola, et al. [39]. One milliliter of extract or standard solution prepared as aforementioned was mixed with $200 \mu \mathrm{L}$ of $2 \mathrm{M}$ sodium hydroxide and $300 \mu \mathrm{L}$ of saturated sodium bicarbonate (all from Sigma-Aldrich). Two milliliters of dansyl chloride (Sigma-Aldrich) solution $(10 \mathrm{mg} / \mathrm{mL})$ in acetone were added to the mixture and incubated at $40{ }^{\circ} \mathrm{C}$ for $45 \mathrm{~min}$. The residual dansyl chloride was removed by adding $100 \mu \mathrm{L}$ of $25 \%$ ammonium hydroxide and incubating for $30 \mathrm{~min}$ at $25^{\circ} \mathrm{C}$. Using acetonitrile, the mixture was adjusted to a final volume of $5 \mathrm{~mL}$ and centrifuged at $3000 \times \mathrm{g}$ for $5 \mathrm{~min}$. After filtration using $0.2 \mu \mathrm{m}$ pore-size filters (Millipore), the filtered supernatant was kept at $4{ }^{\circ} \mathrm{C}$ until further analysis using HPLC. 


\subsubsection{Chromatographic Separations}

Chromatographic separation of BAs was conducted according to the method previously developed by Eerola, et al. [39] and modified by Ben-Gigirey, et al. [40]. An HPLC unit (YL9100, YL Instruments Co., Ltd., Anyang, Korea) equipped with a UV/vis detector (YL Instruments) and Autochro-3000 data system (YL Instruments) was used. For chromatographic separation, a Nova-Pak $\mathrm{C}_{18} 4 \mu \mathrm{m}$ column $\left(150 \mathrm{~mm} \times 4.6 \mathrm{~mm}\right.$, Waters, Milford, MA, USA) held at $40{ }^{\circ} \mathrm{C}$ was utilized. The mobile phases were $0.1 \mathrm{M}$ ammonium acetate dissolved in deionized water (solvent $\mathrm{A}$; Sigma-Aldrich) and acetonitrile (solvent B; SK chemicals, Ulsan, Korea) adjusted to a flow rate of $1 \mathrm{~mL} / \mathrm{min}$ with a linear gradient starting from $50 \%$ of solvent B reaching $90 \%$ by $19 \mathrm{~min}$. A $10 \mu \mathrm{L}$ sample was injected and monitored at $254 \mathrm{~nm}$. The limits of detection were approximately $0.1 \mu \mathrm{g} / \mathrm{mL}$ for all BAs in standard solutions and bacterial cultures, and about $0.1 \mathrm{mg} / \mathrm{kg}$ for all BAs in food matrices [42].

\subsection{Gene Expression Analyses in Bacterial Cultures and Cheonggukjang}

\subsubsection{RNA Extraction and Reverse Transcription}

Expression analysis of tyrosine decarboxylase gene $(t d c)$ involved RNA extraction from bacterial cultures (for in vitro experiments) and Cheonggukjang samples (viz., Cheonggukjang groups prepared through fermentation; for in situ fermentation experiments) with a Ribo-Ex Total RNA isolation solution (Geneall, Seoul, Korea). The extraction was conducted according to the manufacturer's instructions with minor modifications as follows. To prepare bacterial culture for in vitro gene expression analysis, a loopful $(10 \mu \mathrm{L})$ of glycerol stock of each enterococcal strain was inoculated in $5 \mathrm{~mL}$ of MRS broth supplemented with $0.5 \%$ L-histidine monohydrochloride monohydrate, L-tyrosine disodium salt hydrate, L-ornithine monohydrochloride, L-lysine monohydrochloride ( $\mathrm{pH} 5.8$ ), and 0.0005\% pyridoxal- $\mathrm{HCl}$ (all from Sigma-Aldrich) and incubated at $37^{\circ} \mathrm{C}$ for $48 \mathrm{~h}$. Approximately $100 \mu \mathrm{L}$ of the broth culture was then transferred to another tube containing $5 \mathrm{~mL}$ of the same medium and incubated under the same conditions. As for Cheonggukjang samples, $10 \mathrm{~g}$ of Cheonggukjang were gently mixed with $40 \mathrm{~mL}$ of phosphate buffer in a sterile bag, and the liquid part was collected. Subsequently, $3 \mathrm{~mL}$ of the bacterial culture or all liquid part of the mixture were immediately transferred into a $50 \mathrm{~mL}$ conical tube and centrifuged at $10,000 \times g$ at $4{ }^{\circ} \mathrm{C}$ for $5 \mathrm{~min}$. After removing the supernatant, the pellet was suspended with $7 \mathrm{~mL}$ of phosphate buffer and centrifuged under the same conditions. Then, the pellet was homogenized with $800 \mu \mathrm{L}$ of Ribo-Ex reagent in a bacterial lysing tube (Lysing Matrix B; MP Biomedicals, Santa Ana, CA, USA) using a Precellys 24 homogenizer (Bertin Technologies, Montigny, France) with two cycles for $30 \mathrm{~s}$ at $6800 \mathrm{rpm}$, pausing for $90 \mathrm{~s}$ between cycles. Approximately $200 \mu \mathrm{L}$ of chloroform were added to the lysate, vortexed, and centrifuged at $10,000 \times g$ for $1 \mathrm{~min}$. Approximately $400 \mu \mathrm{L}$ of the supernatant were mixed with $600 \mu \mathrm{L}$ of chilled absolute ethanol. The mixture was reacted at $-70{ }^{\circ} \mathrm{C}$ for $15 \mathrm{~min}$ and purified with a Nucleospin RNA kit (Macherey-Nagel, Düren, Germany) according to the manufacturer's instructions. The quality of the extracted RNA was evaluated using a NanoDrop 1000 spectrophotometer (Thermo Fisher, Waltham, MA, USA).

ReverTra Ace qPCR RT Master Mix with gDNA Remover kit (Toyobo, Osaka, Japan) containing reverse transcriptase, RNase inhibitor, oligo (dT) primers, random primers, and deoxynucleoside triphosphates (dNTPs) was used to synthesize cDNA from $1 \mu \mathrm{L}$ of extracted RNA according to the manufacturer's instructions. Reverse transcription was conducted under the following conditions: $37^{\circ} \mathrm{C}$ for $15 \mathrm{~min}, 50^{\circ} \mathrm{C}$ for $5 \mathrm{~min}$, and $98^{\circ} \mathrm{C}$ for $5 \mathrm{~min}$. After the reaction, the resulting cDNA was stored at $-70^{\circ} \mathrm{C}$ until quantitative PCR analysis.

\subsubsection{Quantitative PCR Analysis}

As designed by Kang, et al. [43], $q$-tdc F (5'-AGACCAAGTAATTCCAGTGCC-3') and $q$ - $t d c$ R (5'-CACCGACTACACCTAAGATTGG-3') primers were used for the quantitation of $t d c$ gene expression by E. faecium. The primers for reference genes including q-gap $\mathrm{F}$ (5'-ATACGACACAACTCAAGGACG-3') and $q$-gap R (5'-GATATCTACGCCTAGTTCGCC-3') [34], along with tufA-RT F (5'-TACACGCCACTAC 
GCTCAC-3') and tufA-RT R (5'-AGCTCCGTCCATTTGAGCAG-3') [44] were used for the normalization of $t d c$ gene expression. The efficiency of each set of primers for reverse transcription quantitative polymerase chain reaction (RT-qPCR) was determined by the following equation: $E=10^{(-1 / S)}-1$, where $E$ is the amplification efficiency and $S$ is the slope of standard curves generated through threshold cycle $(\mathrm{Ct})$ values of serial dilutions of cDNA obtained from reverse-transcription of RNA from E. faecium KCCM 12118.

For the RT-qPCR analysis of $t d c$ gene expression in bacterial cultures and Cheonggukjang samples, $5 \mu \mathrm{L}$ of a 10 -fold diluted cDNA were added to $15 \mu \mathrm{L}$ of a master mix containing $10 \mu \mathrm{L}$ of Power SYBR Green PCR Master Mix (Applied Biosystems, Foster City, CA, USA), $3 \mu \mathrm{L}$ of RNase free water, and $1 \mu \mathrm{L}$ of each primer (forward and reverse; $500 \mathrm{nM}$ ). Subsequently, thermal cycling was conducted using an Applied Biosystems 7500 Real-Time PCR system (Applied Biosystems) with the thermal cycling conditions programmed as follows: initial denaturation at $95^{\circ} \mathrm{C}$ for $10 \mathrm{~min} ; 40$ cycles at $95^{\circ} \mathrm{C}$ for $15 \mathrm{~s}$ (denaturation step), and $60^{\circ} \mathrm{C}$ for $60 \mathrm{~s}$ (annealing and elongation steps, unless otherwise mentioned). Annealing and elongation conditions for primer $t u f A$-RT were set at $55^{\circ} \mathrm{C}$ for $60 \mathrm{~s}$. Melting curve analysis was conducted using the RT-PCR system to confirm the specificity and to analyze the amplified products. Ct values were detected when the emissions from fluorescence exceeded the fixed threshold automatically determined by thermocycler software. Relative expression of $t d c$ genes was further calculated by the $2^{-(\Delta \Delta \mathrm{ct})}$ method, normalized to the expression levels detected in E. faecium KCCM 12118 (refer to Figure 2) or Cheonggukjang groups fermented at $37^{\circ} \mathrm{C}$ (refer to Figure 6), and expressed as n-fold differences to compare gene expression levels in different bacterial cultures and Cheonggukjang samples.

\subsection{Statistical Analyses}

Data were presented as means and standard deviations of duplicates or triplicates. All measurements on retail products were performed in triplicates, while the other experiments were conducted in duplicate. The significance of differences was determined by one-way analysis of variance (ANOVA) with Fisher's pairwise comparison module of the Minitab statistical software, version 17 (Minitab Inc., State College, PA, USA), and differences with probability ( $p$ ) value of $<0.05$ were considered statistically significant.

\section{Results and Discussion}

\subsection{Physicochemical Properties of Retail Cheonggukjang Products}

Physicochemical and microbial properties as well as BA content in retail Cheonggukjang products were analyzed to estimate the contributing factors to BA content (particularly tyramine) in Cheonggukjang (Sections 3.1-3.3). Table 1 displays the physicochemical properties of Cheonggukjang products purchased from retail markets in the Republic of Korea. The $\mathrm{pH}$ ranged from 6.39 to 7.05 , with an average $\mathrm{pH}$ of $6.84 \pm 0.23$ (mean \pm standard deviation). The results were similar to the study conducted by Lee, et al. [45], which reported the average $\mathrm{pH}$ of Cheonggukjang to be $7.0 \pm 0.8$. Jeon, et al. [19] and Yoo, et al. [46] also reported the average $\mathrm{pH}$ of Cheonggukjang to be $\mathrm{pH} 6.07 \pm 0.72$ (range of $\mathrm{pH}$ 4.62-8.14) and $\mathrm{pH} 7.21 \pm 0.59$ (range of $\mathrm{pH}$ 5.89-7.95), respectively. Such differences in the $\mathrm{pH}$ of the Cheonggukjang products may be owing to different fermentation conditions [47] and/or fermentation metabolites [48]. The salinity of retail Cheonggukjang products ranged from 1.95 to $9.36 \%$ with an average salinity of $5.16 \pm 2.78 \%$. In comparison, Ko, et al. [18], Jeon, et al. [19], and Kang, et al. [49] reported the average salinity of Cheonggukjang to be $2.12 \pm 1.66 \%(0.12-11.51 \%), 1.56 \pm 1.19 \%(0.10-5.33 \%)$, and $3.51 \pm 2.45$ $(1.64-8.39 \%)$, respectively. Though the salinity of the Cheonggukjang products was found to vary substantially, Ko, et al. [18] suggested that the large differences in Cheonggukjang salinities may be traced to the production process, as some methods utilize the addition of different amounts of salt to preserve the fermented soybean product. The water activity of retail Cheonggukjang products ranged from 0.919 to 0.973 with an average of $0.951 \pm 0.019$. In a previous study by Kim, et al. [47], the average 
water activity was found to be $0.962 \pm 0.028(0.857-0.991)$. Overall, the physicochemical properties of retail Cheonggukjang products analyzed in the current study were mostly similar to the values reported in previous studies. Although the results of the current study did not show any correlation between physicochemical properties and BA content (especially tyramine) based on linear regression analyses (data not shown), it is noteworthy that the ranges of the physicochemical parameters were within the specific conditions for the growth of E. faecium, which are as follows: $\mathrm{pH}$, from 4 to 10 [50]; salinity, up to $7 \%$ [50]; water activity, above 0.940 [51].

Table 1. Physicochemical properties of retail Cheonggukjang products.

\begin{tabular}{cccc}
\hline Products $^{\mathbf{1}}$ & $\mathbf{p H}$ & Salinity (\%) & Water Activity \\
\hline $\mathrm{CJ} 1$ & $6.91 \pm 0.03^{2}$ & $5.54 \pm 0.09$ & $0.948 \pm 0.002$ \\
$\mathrm{CJ} 2$ & $6.84 \pm 0.02$ & $7.25 \pm 0.06$ & $0.919 \pm 0.001$ \\
$\mathrm{CJ} 3$ & $6.87 \pm 0.02$ & $3.16 \pm 0.06$ & $0.968 \pm 0.002$ \\
$\mathrm{CJ} 4$ & $6.99 \pm 0.03$ & $1.95 \pm 0.09$ & $0.973 \pm 0.002$ \\
CJ5 & $7.05 \pm 0.05$ & $9.36 \pm 0.59$ & $0.944 \pm 0.003$ \\
CJ6 & $6.39 \pm 0.03$ & $3.71 \pm 0.34$ & $0.954 \pm 0.003$ \\
\hline Average & $6.84 \pm 0.23$ & $5.16 \pm 2.78$ & $0.951 \pm 0.019$ \\
\hline${ }^{\text {CJ: } \text { Cheonggukjang; }}{ }^{2}$ Mean \pm standard deviation were calculated from triplicate experiments.
\end{tabular}

\subsection{Microbial Properties of Retail Cheonggukjang Products}

Table 2 shows the microbial properties of retail Cheonggukjang products. The number of total mesophilic viable bacteria ranged from 8.54 to $9.81 \mathrm{Log} C F U / g$, with an average of $9.27 \pm 0.45 \mathrm{Log} \mathrm{CFU} / \mathrm{g}$. Comparatively, Ko, et al. [18] and Jeon, et al. [19] reported the total counts of viable mesophilic bacteria of Cheonggukjang products to be $7.50 \pm 1.01 \mathrm{Log}$ CFU/g (5.30-9.98 Log CFU/g) and $9.65 \pm 0.77 \mathrm{Log}$ CFU/g (8.23-11.66 Log CFU/g), respectively. The wide range of total mesophilic viable bacteria may result from an insufficient standardization of Cheonggukjang manufacturing processes such as different fermentation materials and conditions [18,47]. Enterococcus spp. were detected at concentrations of 6.64-7.99 Log $\mathrm{CFU} / \mathrm{g}$, with an average of $7.17 \pm 0.49 \mathrm{Log} \mathrm{CFU} / \mathrm{g}$. The number of lactic acid bacteria was found to be approximately 6.66-8.12 Log CFU/g, with an average of 7.09 $\pm 0.58 \mathrm{Log} C F U / g$ (Table 2). For comparison, a study by Kang and Park [25] showed that Enterococcus spp. were detected in all 31 Cheonggukjang products at concentrations of 3.51-8.46 Log CFU/g, with an average of $5.95 \pm 1.60 \mathrm{Log} C F U / \mathrm{g}$. In the report, approximately $58 \%$ and $16.8 \%$ of the isolated Enterococcus strains were identified as E. faecium and E. faecalis, respectively. The presence of E. faecium in Cheonggukjang was also reported by Kang, et al. [26]. The reported results on the presence of Enterococcus spp. at high concentrations in Cheonggukjang concurred with the findings of the current study. As E. faecium has been reported as a pathogenic and/or tyramine-producing bacterium detected in some foods including Chinese and Japanese fermented soybean products, previous studies have mentioned that preventative measures are necessary to avoid contamination during the manufacturing of fermented foods [52-55]. The traditional Cheonggukjang production process may also be susceptible to contamination by harmful microbes owing to the reliance on rice straw containing $B$. subtilis for fermentation [56]. In fact, according to Heu, et al. [57], rice straw contains a variety of bacteria, including mesophiles, thermophiles, coliforms, and actinomycetes, as well as fungi. Moreover, as sterilization processes are not utilized in the manufacturing of Cheonggukjang, occasional contamination by tyramine-producing bacteria such as E. faecium may be present in the final product. The results of the current and previous studies suggest that further research appears to be necessary for the development of methods to inhibit E. faecium growth during the manufacturing of Cheonggukjang as well as other fermented soybean products described above. 
Table 2. Microbial properties of retail Cheonggukjang products.

\begin{tabular}{cccc}
\hline Products $^{1}$ & $\begin{array}{c}\text { Total Mesophilic Viable } \\
\text { Bacteria (Log CFU/g) }\end{array}$ & $\begin{array}{c}\text { Enterococcus spp. } \\
\text { (Log CFU/g) }\end{array}$ & $\begin{array}{c}\text { Lactic Acid Bacteria } \\
\text { (Log CFU/g) }\end{array}$ \\
\hline CJ1 & $9.45 \pm 0.06^{2}$ & $7.32 \pm 0.03$ & $7.45 \pm 0.10$ \\
CJ2 & $9.04 \pm 0.09$ & $6.78 \pm 0.14$ & $6.66 \pm 0.10$ \\
CJ3 & $9.81 \pm 0.25$ & $6.64 \pm 0.01$ & $6.70 \pm 0.15$ \\
CJ4 & $9.57 \pm 0.15$ & $7.27 \pm 0.03$ & $6.96 \pm 0.09$ \\
CJ5 & $8.54 \pm 0.48$ & $7.00 \pm 0.08$ & $6.67 \pm 0.18$ \\
CJ6 & $9.20 \pm 0.44$ & $7.99 \pm 0.04$ & $8.12 \pm 0.01$ \\
\hline Average & $9.27 \pm 0.45$ & $7.17 \pm 0.49$ & $7.09 \pm 0.58$ \\
\hline
\end{tabular}

${ }^{1}$ CJ: Cheonggukjang; ${ }^{2}$ Mean \pm standard deviation were calculated from triplicate experiments; CFU: colonyforming units.

\subsection{BA Content of Retail Cheonggukjang Products}

Cheonggukjang contains abundant BA precursor amino acids such as lysine, histidine, tyrosine, and phenylalanine [58]. The high amino acid content may pose a risk for conversion into BAs during Cheonggukjang fermentation. In the present study, tryptamine, $\beta$-phenylethylamine, putrescine, cadaverine, histamine, tyramine, spermidine, and spermine contents in retail Cheonggukjang products were detected at concentrations of $70.63 \pm 44.74 \mathrm{mg} / \mathrm{kg}, 36.22 \pm 29.55 \mathrm{mg} / \mathrm{kg}$, $10.80 \pm 5.07 \mathrm{mg} / \mathrm{kg}, 18.57 \pm 9.08 \mathrm{mg} / \mathrm{kg}, 8.37 \pm 2.40 \mathrm{mg} / \mathrm{kg}, 457.42 \pm 573.15 \mathrm{mg} / \mathrm{kg}, 121.92 \pm 19.69 \mathrm{mg} / \mathrm{kg}$, and $187.20 \pm 110.27 \mathrm{mg} / \mathrm{kg}$, respectively (Table 3). A previous study suggested toxicity limits of $30 \mathrm{mg} / \mathrm{kg}$ for $\beta$-phenylethylamine, $100 \mathrm{mg} / \mathrm{kg}$ for histamine, and $100-800 \mathrm{mg} / \mathrm{kg}$ for tyramine in foods [21]. Therefore, the evaluation of the BA content of the Cheonggukjang products was continued with regard to the aforementioned BA intake limits with the exception of tyramine (at $100 \mathrm{mg} / \mathrm{kg})$. Evaluation of $\beta$-phenylethylamine content in two Cheonggukjang products revealed that concentrations exceeded the recommended limit of $30 \mathrm{mg} / \mathrm{kg}$, with one product exceeding the limit by a factor of approximately 3. Though the histamine content of all Cheonggukjang products was found to be below the recommended limit of $100 \mathrm{mg} / \mathrm{kg}$, the tyramine content of three products exceeded the $100 \mathrm{mg} / \mathrm{kg}$ limit by factors of 2, 9, and 14, respectively. Other studies have reported similarly high concentrations of tyramine in Cheonggukjang. Ko, et al. [18] and Seo, et al. [20] reported the highest concentrations of tyramine in Cheonggukjang products, exceeding the recommended limit by factors of 19 and 9, respectively. Furthermore, Cho, et al. [59], Han, et al. [60], and Jeon, et al. [19] reported that Cheonggukjang products contained high concentrations of tyramine, which exceeded the recommended limit by up to factors of 5,5 , and 3 , respectively. Altogether, as $\beta$-phenylethylamine and tyramine content of several Cheonggukjang products exceeded the recommended limits, overconsumption of such fermented soybean products may occasionally result in adverse effects on the body. Moreover, Cheonggukjang was found to contain other BAs enhancing the toxicity of $\beta$-phenylethylamine and tyramine. Therefore, further research remains necessary for precautionary measures and remedial methods to reduce the BA content of Cheonggukjang to ensure the safety of the fermented soybean food. 
Table 3. Biogenic amine (BA) content of retail Cheonggukjang products.

\begin{tabular}{|c|c|c|c|c|c|c|c|c|}
\hline \multirow{2}{*}{ Products ${ }^{1}$} & \multicolumn{8}{|c|}{ BA Content $(\mathrm{mg} / \mathrm{kg})^{2}$} \\
\hline & TRP & PHE & PUT & CAD & HIS & TYR & SPD & SPM \\
\hline CJ1 & $\begin{array}{l}115.06 \pm \\
19.72 \mathrm{~A}, 3\end{array}$ & $\begin{array}{c}31.66 \pm \\
3.82^{\mathrm{B}}\end{array}$ & $\begin{array}{c}8.54 \pm \\
3.45^{\mathrm{BC}}\end{array}$ & $\begin{array}{c}22.66 \pm \\
0.82^{\mathrm{C}}\end{array}$ & $\begin{array}{l}8.60 \pm \\
0.88^{\mathrm{B}}\end{array}$ & $\begin{array}{c}222.25 \pm \\
15.1^{C}\end{array}$ & $\begin{array}{c}137.88 \pm \\
1.76^{\mathrm{A}}\end{array}$ & $\begin{array}{c}292.99 \pm \\
27.86^{\mathrm{A}}\end{array}$ \\
\hline $\mathrm{CJ} 2$ & $\begin{array}{c}86.02 \pm \\
3.12^{\mathrm{B}}\end{array}$ & $\begin{array}{c}16.06 \pm \\
2.24^{\mathrm{B}}\end{array}$ & $\begin{array}{c}12.18 \pm \\
0.73^{\mathrm{B}}\end{array}$ & $\begin{array}{c}29.95 \pm \\
0.82 \mathrm{~A}\end{array}$ & $\begin{array}{c}12.69 \pm \\
0.28^{\mathrm{A}}\end{array}$ & $\begin{array}{c}57.14 \pm \\
8.06^{\mathrm{D}}\end{array}$ & $\begin{array}{c}99.99 \pm \\
4.25^{\mathrm{C}}\end{array}$ & $\begin{array}{c}206.32 \pm \\
23.82^{\text {B }}\end{array}$ \\
\hline $\mathrm{CJ} 3$ & $\begin{array}{c}118.27 \pm \\
5.97^{\mathrm{A}}\end{array}$ & $\begin{array}{c}27.22 \pm \\
2.00^{\mathrm{B}}\end{array}$ & $\begin{array}{c}18.33 \pm \\
4.93 \mathrm{~A}\end{array}$ & $\begin{array}{c}26.58{ }^{ \pm} \\
1.65^{\mathrm{B}}\end{array}$ & $\begin{array}{l}6.50 \pm \\
1.00^{\mathrm{C}}\end{array}$ & $\begin{array}{c}80.83 \pm \\
3.91 \mathrm{D}\end{array}$ & $\begin{array}{c}96.82 \pm \\
4.09^{\mathrm{C}}\end{array}$ & $\begin{array}{c}201.63 \pm \\
5.77^{\mathrm{B}}\end{array}$ \\
\hline $\mathrm{CJ} 4$ & $\begin{array}{c}54.87 \pm \\
3.18 \mathrm{C}\end{array}$ & $\begin{array}{c}22.20^{ \pm} \\
7.06^{\mathrm{B}}\end{array}$ & $\begin{array}{c}11.36 \pm \\
2.28^{\mathrm{B}}\end{array}$ & $\begin{array}{l}8.28 \pm \\
0.54 \mathrm{~F}\end{array}$ & $\begin{array}{l}5.86 \pm \\
0.37^{\mathrm{C}}\end{array}$ & $\begin{array}{c}898.41 \pm \\
79.43^{\text {B }}\end{array}$ & $\begin{array}{c}125.61 \pm \\
4.64^{\mathrm{B}}\end{array}$ & $\begin{array}{l}91.09 \pm \\
24.03 \mathrm{C}\end{array}$ \\
\hline CJ5 & $\begin{array}{c}47.85 \pm \\
4.04 \mathrm{C}\end{array}$ & $\begin{array}{c}24.48 \pm \\
1.97^{\mathrm{B}}\end{array}$ & $\begin{array}{c}11.61 \pm \\
4.21^{\mathrm{B}}\end{array}$ & $\begin{array}{c}13.57 \pm \\
0.21 \mathrm{D}\end{array}$ & $\begin{array}{l}8.65 \pm \\
0.51^{\mathrm{B}}\end{array}$ & $\begin{array}{c}61.98 \pm \\
6.30^{\mathrm{D}}\end{array}$ & $\begin{array}{c}125.98 \pm \\
7.60^{\mathrm{B}}\end{array}$ & $\begin{array}{c}305.05 \pm \\
17.35^{\mathrm{A}}\end{array}$ \\
\hline CJ6 & $\begin{array}{l}1.70 \pm \\
2.94^{\mathrm{D}}\end{array}$ & $\begin{array}{l}95.58 \pm \\
46.97 \mathrm{~A}\end{array}$ & $\begin{array}{l}2.81 \pm \\
1.77^{\mathrm{C}}\end{array}$ & $\begin{array}{c}10.19 \pm \\
0.50^{\mathrm{E}}\end{array}$ & $\begin{array}{l}7.84 \pm \\
0.33^{\mathrm{B}}\end{array}$ & $\begin{array}{c}1424.04 \pm \\
62.43 \mathrm{~A}\end{array}$ & $\begin{array}{c}145.18 \pm \\
7.64 \mathrm{~A}\end{array}$ & $\begin{array}{c}26.20 \pm \\
8.51^{\mathrm{D}}\end{array}$ \\
\hline Average & $\begin{array}{c}70.63 \pm \\
44.74\end{array}$ & $\begin{array}{c}36.22 \pm \\
29.55\end{array}$ & $\begin{array}{c}10.80 \pm \\
5.07\end{array}$ & $\begin{array}{c}18.57 \pm \\
9.08\end{array}$ & $\begin{array}{c}8.37 \pm \\
2.40\end{array}$ & $\begin{array}{c}457.42 \pm \\
573.15\end{array}$ & $\begin{array}{c}121.92 \pm \\
19.69\end{array}$ & $\begin{array}{c}187.20 \pm \\
110.27\end{array}$ \\
\hline
\end{tabular}

${ }^{1}$ CJ: Cheonggukjang; ${ }^{2}$ TRP: tryptamine, PHE: $\beta$-phenylethylamine, PUT: putrescine, CAD: cadaverine, HIS: histamine, TYR: tyramine, SPD: spermidine, SPM: spermine; ${ }^{3}$ Mean \pm standard deviation were calculated from triplicate experiments. Mean values in the same column followed by different letters (A-F) are significantly different $(p<0.05)$.

\subsection{In Vitro BA Production by Enterococcus Strains Isolated from Retail Cheonggukjang Products}

Microbial decarboxylation of free amino acids is one of the main causing factors in the production of BAs, and various microorganisms, including Bacillus, Clostridium, Enterobacteriaceae, enterococci, Lactobacillus, and Pseudomonas, are capable of producing the decarboxylases responsible for the conversion of amino acids into BAs $[21,61,62]$. Considering previous studies in which Enterococcus spp. have been suggested to be responsible for tyramine accumulation in Chinese and Japanese fermented soybean products [52,53], the current study analyzed the BA production capabilities of 169 enterococcal strains isolated from retail Cheonggukjang products using an MRS broth-based assay medium. As shown in Figure 1 , the production of tryptamine, $\beta$-phenylethylamine, putrescine, cadaverine, spermidine, and spermine was observed at concentrations lower than $10 \mu \mathrm{g} / \mathrm{mL}$. Histamine production by 168 of the 169 strains was detected at quantities lower than $2 \mu \mathrm{g} / \mathrm{mL}$; however, only one strain was capable of producing histamine at $96.06 \mu \mathrm{g} / \mathrm{mL}$. Though tyramine production ranged from ND (not detected) to $315.29 \mu \mathrm{g} / \mathrm{mL}, 157$ strains (about 93\%) produced over $100 \mu \mathrm{g} / \mathrm{mL}$. Through $16 \mathrm{~S}$ rRNA sequencing, the seven strains (CJE 101, CJE 115, CJE 119, CJE 128, CJE 130, CJE 210, and CJE 216) that produced the highest levels of tyramine (301.14-315.29 $\mu \mathrm{g} / \mathrm{mL}$; refer to Figure 2) among the enterococcal strains were all identified as E. faecium. Novella-Rodríguez, et al. [63] suggested that the presence of Enterobacteriaceae or enterococci may result in the production of BAs in contaminated food products. Marcobal, et al. [64] demonstrated that E. faecium possesses a gene that codes an enzyme capable of L-tyrosine decarboxylation. According to Ibe, et al. [22], high levels of tyramine in Miso (a Japanese fermented soybean paste) products may partially result from tyramine production by E. faecium. Jeon, et al. [19] reported that Enterococcus spp. exhibited strong production of tyramine ranging from $0.41 \mu \mathrm{g} / \mathrm{mL}$ to $351.59 \mu \mathrm{g} / \mathrm{mL}$ in assay media. The author also found tyramine-producing Bacillus spp. (up to $123.08 \mu \mathrm{g} / \mathrm{mL}$ ) and suggested that the species is one of the major tyramine producers in Cheonggukjang along with Enterococcus species based on the in situ fermentation experiment. Consequently, the present results suggest that Enterococcus spp. (particularly E. faecium) may be largely responsible for high tyramine concentrations in Cheonggukjang. 


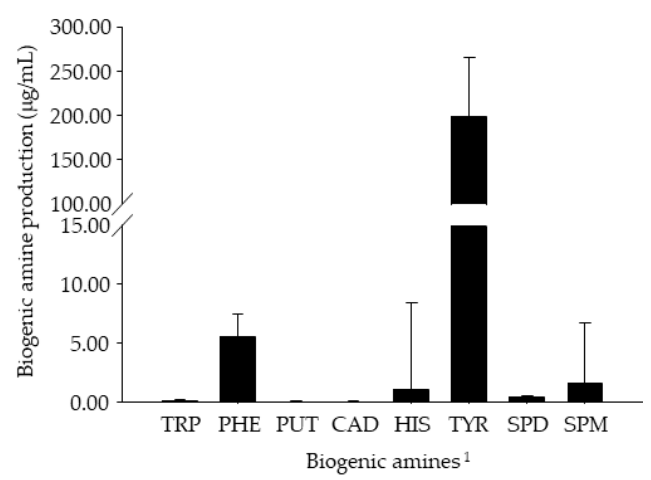

Figure 1. Biogenic amine (BA) production by Enterococcus strains $(n=169)$ isolated from retail Cheonggukjang products. Error bars indicate standard deviations calculated from duplicate experiments. ${ }^{1}$ TRP: tryptamine, PHE: $\beta$-phenylethylamine, PUT: putrescine, CAD: cadaverine, HIS: histamine, TYR: tyramine, SPD: spermidine, SPM: spermine.



Figure 2. Comparison of tyramine production and $t d c$ expression by E. faecium strains. $\mathbf{\square}$ : tyramine production, $\square: t d c$ gene expression. The expression levels observed in E. faecium strains isolated from retail Cheonggukjang products were normalized to that detected in E. faecium KCCM 12118 (type strain). The $t d c$ gene expression was not detected in E. faecium strain CJE 210. Mean values followed by different letters are significantly different $(p<0.05)$. Error bars indicate standard deviations calculated from duplicate experiments.

3.5. Selection of Tyramine-Producing E. faecium Strain for Cheonggukjang Fermentation Based on Tyrosine Decarboxylase Gene Expression In Vitro

In the current study, the efficiency of primer sets $q$ - $t d c$ (for the quantitation of $t d c$ gene expression) along with $q$-gap and $t u f A$-RT (for the normalization of $t d c$ gene expression) was calculated to be $100.71 \%, 94.84 \%$, and 95.03\%, respectively. An amplification efficiency between 90 and 110\% indicates that the results of gene expression obtained using RT-qPCR are reproducible [65].

The aforementioned primer sets were used to detect $t d c$ gene expression by the seven E. faecium strains (CJE 101, CJE 115, CJE 119, CJE 128, CJE 130, CJE 210, and CJE 216) with the highest tyramine production in vitro as described in the previous section (note that the primer sets were also used for in situ gene expression analysis). Among the strains, E. faecium strain CJE 216 showed the highest expression level of $t d c$ gene (Figure 2). Considering the highest $t d c$ gene expression as well as tyramine production in vitro, the CJE 216 strain was selected as an inoculant for fermentation experiments in the next section.

\subsection{Tyramine Production by E. faecium during Cheonggukjang Fermentation at Various Temperatures}

3.6.1. Changes in Physicochemical and Microbial Properties during Cheonggukjang Fermentation at Various Temperatures

As the results of the previous sections indicated that E. faecium was most likely one of the major contributing factors to high levels of tyramine in Cheonggukjang, in situ fermentation experiments were 
performed to empirically investigate the influence of E. faecium on tyramine content in Cheonggukjang. For the in situ fermentation experiments, three experimental groups of Cheonggukjang were used: control group inoculated with only B. subtilis KCTC 3135, and other two groups co-inoculated with the B. subtilis strain and each E. faecium strain (E. faecium KCCM 12118 or E. faecium CJE 216). Each group was further divided into three groups based on fermentation temperatures of $25^{\circ} \mathrm{C}, 37^{\circ} \mathrm{C}$, and $45^{\circ} \mathrm{C}$ (low-, intermediate-, and high-temperature groups, respectively). As shown in Figure 3, the changes in the physicochemical and microbial properties of Cheonggukjang were measured at 24-hour intervals for 3 days of fermentation. The $\mathrm{pH}$ of all Cheonggukjang groups was lowest on day 2, with progressively lower $\mathrm{pH}$ depending on the fermentation temperature, independent of which inoculum was used. The $\mathrm{pH}$ on day 2 of Cheonggukjang fermentation at $25^{\circ} \mathrm{C}, 37^{\circ} \mathrm{C}$, and $45^{\circ} \mathrm{C}$ ranged from $\mathrm{pH} 6.34$ to 6.36, pH 5.90 to 6.09, and pH 5.49 to 5.88, respectively (Figure 3a). Loizzo, et al. [66] suggested that decarboxylases are produced by bacteria owing to a mechanism to neutralize acidic environments that restrict the growth of the bacteria. A previous study reported that low $\mathrm{pH}$ between 4.0 and 5.5 may result in the production of BAs [67]. Therefore, in this study, as the Cheonggukjang groups fermented at $45^{\circ} \mathrm{C}$ (high-temperature group) resulted in a lower $\mathrm{pH}$ than other groups fermented at $37^{\circ} \mathrm{C}$ and $25^{\circ} \mathrm{C}$ (intermediate- and low-temperature groups, respectively), regardless of inoculum, the BA content was expected to be detected at the highest concentration among all Cheonggukjang groups. As for water activity, all Cheonggukjang groups remained within 0.95-0.97 during fermentation (Figure 3b).
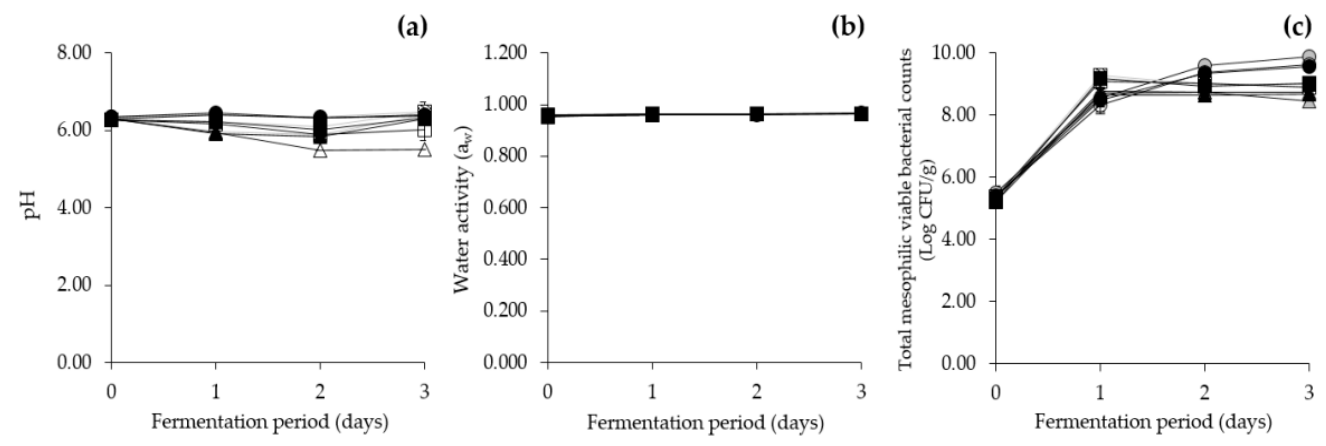

Figure 3. Physicochemical and microbial properties during Cheonggukjang fermentation at various temperatures. (a) $\mathrm{pH},(\mathbf{b})$ water activity, (c) total mesophilic viable bacterial counts. $\bullet: 25^{\circ} \mathrm{C}, \square: 37^{\circ} \mathrm{C}$, $\Delta: 45^{\circ} \mathrm{C}$ (inoculated with only B. subtilis KCTC 3135); •: $25^{\circ} \mathrm{C}$, $\mathbf{~}: 37^{\circ} \mathrm{C}, \mathbf{\Delta}: 45^{\circ} \mathrm{C}$ (inoculated with B. subtilis KCTC 3135 and E. faecium KCCM 12118); $\circ: 25^{\circ} \mathrm{C}, \square: 37^{\circ} \mathrm{C}, \triangle: 45^{\circ} \mathrm{C}$ (inoculated with $B$. subtilis KCTC 3135 and E. faecium CJE 216). Error bars indicate standard deviations calculated from duplicate experiments.

The counts of total mesophilic viable bacteria, most probably attributed to B. subtilis inoculated, showed that microbial concentrations started from approximately $6 \mathrm{Log} C \mathrm{CU} / \mathrm{g}$ on day 0 and remained at approximately 8-9 Log CFU/g throughout Cheonggukjang fermentation at all three temperatures, regardless of the presence or absence of E. faecium inoculum (Figure 3c). The total mesophilic viable bacteria in Cheonggukjang increased as fermentation temperature decreased; however, on day 1 , those in the groups fermented at $25^{\circ} \mathrm{C}$ and $45^{\circ} \mathrm{C}$ showed growth up to $8 \mathrm{Log} \mathrm{CFU} / \mathrm{g}$, while those in the groups fermented at $37^{\circ} \mathrm{C}$ exhibited the highest counts at $9 \mathrm{Log} \mathrm{CFU} / \mathrm{g}$. The results concurred with a previous finding that $37^{\circ} \mathrm{C}$ is the optimal in situ growth temperature for B. subtilis during Cheonggukjang fermentation [29]. Similarly, Mann, et al. [68] reported the optimal in vitro growth temperature for B. subtilis strains isolated from Cheonggukjang to be $37^{\circ} \mathrm{C}$.

The enterococcal count in Cheonggukjang co-inoculated with E. faecium KCCM 12118 at approximately $4 \mathrm{Log}$ CFU/g (and B. subtilis KCTC 3135 at $6 \mathrm{Log}$ CFU/g as well) increased by $1.63 \mathrm{Log}$ $\mathrm{CFU} / \mathrm{g}, 3.52 \mathrm{Log} \mathrm{CFU} / \mathrm{g}$, and $4.06 \mathrm{Log} \mathrm{CFU} / \mathrm{g}$ after 3 days of fermentation at $25^{\circ} \mathrm{C}, 37^{\circ} \mathrm{C}$, and $45^{\circ} \mathrm{C}$, respectively (Figure 4). In Cheonggukjang co-inoculated with E. faecium CJE 216 at $4 \mathrm{Log} \mathrm{CFU} / \mathrm{g}$ (and B. subtilis KCTC 3135), enterococcal count increased at all fermentation temperatures of $25^{\circ} \mathrm{C}$, 
$37^{\circ} \mathrm{C}$, and $45^{\circ} \mathrm{C}$ by $3.48 \mathrm{Log} \mathrm{CFU} / \mathrm{g}, 4.78 \mathrm{Log} \mathrm{CFU} / \mathrm{g}$, and $4.80 \mathrm{Log} \mathrm{CFU} / \mathrm{g}$, respectively, by day 3 . Enterococcus spp. were not detected in the control group for the duration of the fermentation period. The results displayed progressively higher enterococcal counts that increased alongside rising fermentation temperatures with the highest enterococcal counts in Cheonggukjang fermented at $45^{\circ} \mathrm{C}$ (high-temperature group). The findings were comparable to a previous study by Morandi, et al. [69], which showed that lower fermentation temperatures weakened E. faecium growth as the reported generation time at $25^{\circ} \mathrm{C}$ was nearly two times longer than at $37^{\circ} \mathrm{C}$. E. faecium has been reported to display active growth within the temperature range of $37-53^{\circ} \mathrm{C}$, with an optimal growth temperature of $42.7^{\circ} \mathrm{C}[50,70]$. The current and previous studies, therefore, indicate that the use of high fermentation temperatures such as $45^{\circ} \mathrm{C}$ may enhance $E$. faecium growth, thereby increasing the potential for high tyramine production during Cheonggukjang fermentation.
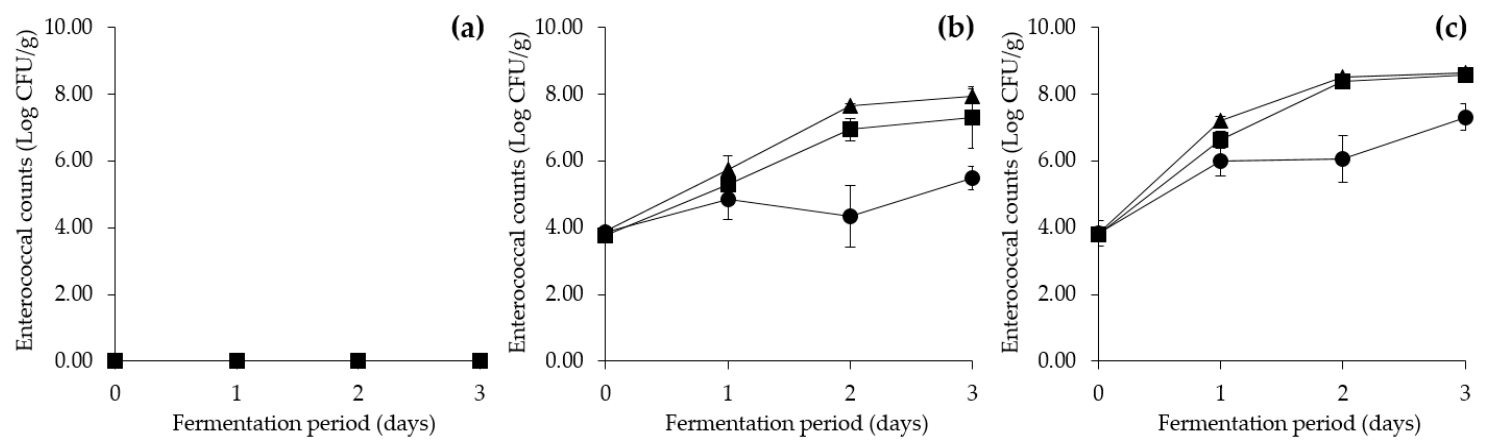

Figure 4. Effect of fermentation temperature on enterococcal counts in Cheonggukjang inoculated with (a) B. subtilis KCTC 3135, (b) B. subtilis KCTC 3135 and E. faecium KCCM 12118, and (c) B. subtilis KCTC 3135 and E. faecium CJE 216. •: $25^{\circ} \mathrm{C}$, $\mathbf{~ : ~} 37^{\circ} \mathrm{C}, \mathbf{\Delta}: 45^{\circ} \mathrm{C}$. Error bars indicate standard deviations calculated from duplicate experiments.

\subsubsection{Effect of Fermentation Temperature on Tyramine Content in Cheonggukjang}

The tyramine content of Cheonggukjang co-inoculated with either E. faecium KCCM 12118 or E. faecium CJE 216, along with B. subtilis KCTC 3135, was measured during fermentation, as seen in Figure 5 . The tyramine content of the control group without $E$. faecium was detected at concentrations that did not exceed $10 \mathrm{mg} / \mathrm{kg}$ in all fermentation conditions (Figure 5a). In contrast, other groups with E. faecium contained higher levels of tyramine, which indicated that E. faecium was capable of and responsible for producing tyramine in Cheonggukjang. In Cheonggukjang groups co-inoculated with E. faecium KCCM 12118, initial tyramine content increased by $0.78 \mathrm{mg} / \mathrm{kg}, 33.36 \mathrm{mg} / \mathrm{kg}$, and $101.17 \mathrm{mg} / \mathrm{kg}$ at 3 days of fermentation at $25^{\circ} \mathrm{C}, 37^{\circ} \mathrm{C}$, and $45^{\circ} \mathrm{C}$, respectively (Figure $5 \mathrm{~b}$ ). As for Cheonggukjang groups co-inoculated with E. faecium CJE 216, initial tyramine content increased by $1.59 \mathrm{mg} / \mathrm{kg}, 74.11 \mathrm{mg} / \mathrm{kg}$, and $85.14 \mathrm{mg} / \mathrm{kg}$ at $25{ }^{\circ} \mathrm{C}, 37{ }^{\circ} \mathrm{C}$, and $45^{\circ} \mathrm{C}$, respectively, by day 3 of fermentation (Figure 5c). All Cheonggukjang groups fermented at $25^{\circ} \mathrm{C}$ contained the lowest tyramine concentrations at less than $10 \mathrm{mg} / \mathrm{kg}$ during the entire fermentation duration. However, at $45^{\circ} \mathrm{C}$, the Cheonggukjang group co-inoculated with E. faecium KCCM 12118 displayed an exceptionally high tyramine content detected at $105.13 \pm 5.68 \mathrm{mg} / \mathrm{kg}$, exceeding the recommended limit, as expected owing to the acidic $\mathrm{pH}$ described in Section 3.6.1. Both E. faecium strains appeared to continuously produce tyramine during Cheonggukjang fermentation at $37^{\circ} \mathrm{C}$ and $45^{\circ} \mathrm{C}$ (Figure $5 \mathrm{~b}, \mathrm{c}$ ). The results of the current study are in agreement with findings reported by Kalhotka, et al. [71], which showed a stronger in vitro tyramine production by E. faecium incubated at $37^{\circ} \mathrm{C}$ than at $25^{\circ} \mathrm{C}$. According to Morandi, et al. [69], E. faecium metabolic activity was detected to be higher at $37^{\circ} \mathrm{C}$ than at $25^{\circ} \mathrm{C}$ during milk fermentation. The previous studies have indicated that lower temperatures may reduce both metabolic activity and tyramine production of E. faecium. BA content during fermentation at higher temperatures may even reach dangerously high levels as reported by Kang, et al. [43]. In the same report, tyramine concentrations in E. faecium-inoculated Cheonggukjang fermented at $45^{\circ} \mathrm{C}$ for 
$48 \mathrm{~h}$ increased (up to $698.67 \mathrm{mg} / \mathrm{kg}$ ) during the fermentation period, and consequently exceeded the recommended limit for consumption. Jeon, et al. [19] also reported strong tyramine production by Enterococcus spp. during soybean fermentation at $37^{\circ} \mathrm{C}$. The report demonstrated that tyramine concentrations continued to increase as fermentation progressed. Given the results, safety precautions regarding the limitation of fermentation duration and temperature appear to be necessary as extended periods of fermentation as well as high fermentation temperatures may increase tyramine content in Cheonggukjang beyond the recommended safe limit for consumption. Besides, the results showing a lower tyramine content in Cheonggukjang during fermentation at lower temperatures coincide with the results in the previous section that displayed a reduction in enterococcal count alongside a decrease in fermentation temperature. Taken together, the present study indicates that lower fermentation temperatures inhibit enterococcal growth, thereby limiting acid production and maintaining low levels of tyramine in Cheonggukjang. Therefore, utilizing lower temperatures for Cheonggukjang fermentation may reduce the risks associated with Enterococcus growth and tyramine accumulation.
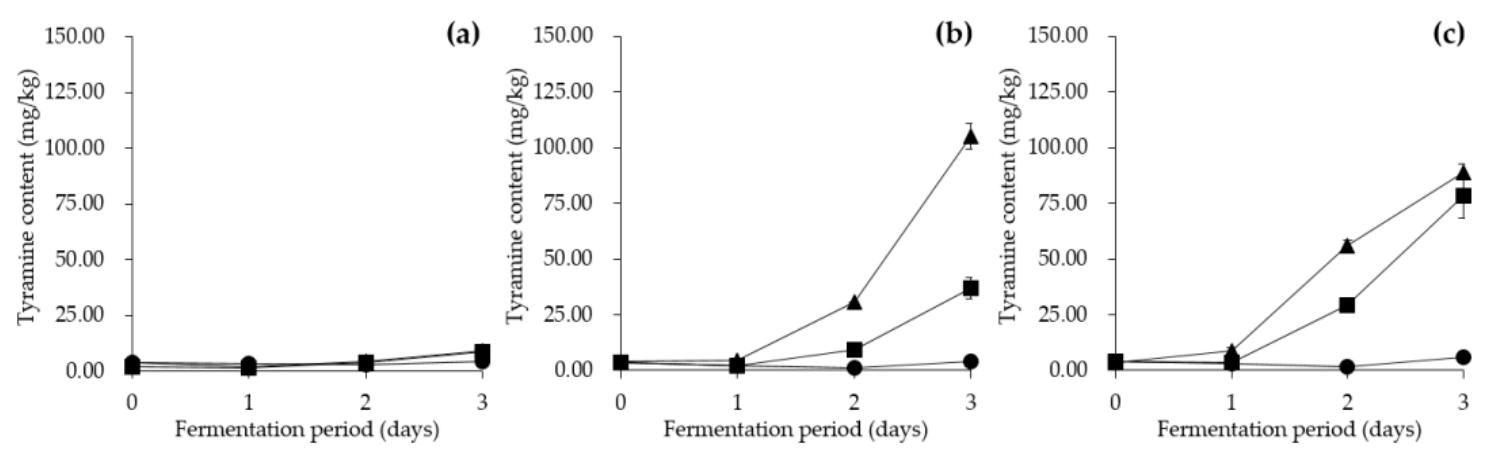

Figure 5. Effect of fermentation temperature on tyramine content in Cheonggukjang inoculated with (a) B. subtilis KCTC 3135, (b) B. subtilis KCTC 3135 and E. faecium KCCM 12118, and (c) B. subtilis KCTC 3135 and E. faecium CJE 216. •: $25^{\circ} \mathrm{C}$, $\mathbf{~ : ~} 37^{\circ} \mathrm{C}, \mathbf{\Delta}: 45^{\circ} \mathrm{C}$. Error bars indicate standard deviations calculated from duplicate experiments.

3.6.3. Effect of Fermentation Temperature on $t d c$ Gene Expression by E. faecium Strains in Cheonggukjang

The changes in $t d c$ gene expression by tyramine-producing E. faecium strains were detected and quantified during fermentation of Cheonggukjang at $25^{\circ} \mathrm{C}, 37^{\circ} \mathrm{C}$, and $45^{\circ} \mathrm{C}$. As Cheonggukjang is mostly fermented at $37^{\circ} \mathrm{C}$, the $t d c$ gene expression detected in Cheonggukjang groups fermented at $45^{\circ} \mathrm{C}$ was normalized to that detected in the corresponding groups fermented at $37^{\circ} \mathrm{C}$ according to the E. faecium strains used as inoculants. In Cheonggukjang fermented at $25^{\circ} \mathrm{C}$, tyramine content continuously remained at concentrations lower than $10 \mathrm{mg} / \mathrm{kg}$, and $t d c$ gene expression by E. faecium KCCM 12118 and E. faecium CJE 216 was not detected in all Cheonggukjang groups. In contrast, the highest $t d c$ gene expression by E. faecium KCCM 12118 was detected in Cheonggukjang fermented at $45^{\circ} \mathrm{C}$ and was upregulated in the range of 1.90- to 7.15-fold throughout Cheonggukjang fermentation, compared with that in Cheonggukjang fermented at $37^{\circ} \mathrm{C}$ (Figure 6a-c, left). As for Cheonggukjang fermented at $45^{\circ} \mathrm{C}$ with E. faecium CJE 216, downregulation of $t d c$ gene expression was observed at 0.82 -fold on day 1 , and the expression was then upregulated in the range of 1.90- to 3.39-fold thereafter (Figure 6a-c, right). Consequently, both tyramine content and $t d c$ gene expression were highest in Cheonggukjang groups fermented at $45^{\circ} \mathrm{C}$ (viz., high-temperature group). Nonetheless, the variation in detected $t d c$ gene expression levels during fermentation did not necessarily reflect the tyramine content observed for Cheonggukjang. After one day of fermentation, the Cheonggukjang group with E. faecium CJE 216 fermented at $37^{\circ} \mathrm{C}$ contained a lower tyramine content than at $45^{\circ} \mathrm{C}$; however, $t d c$ gene expression was slightly higher at $37^{\circ} \mathrm{C}$ as described right above. The results showed that there may be differences between gene expression level and enzyme activity (and products thereof). Glanemann, et al. [72] reported that, in vitro, the mRNA response levels do not necessarily reflect the protein response levels 
or enzyme activity. As previously suggested by Ladero, et al. [73], while the correlation between BA content and gene expression is not always linear, RT-qPCR remains a reliable method to detect and quantify BA-producing bacteria in food products. Similarly, in our preliminary tests conducted under different incubation conditions, tyramine production by E. faecium strains in an assay medium appeared to be insignificantly related to $t d c$ gene expression level (data not shown). Therefore, utilizing HPLC analysis appears to be essential for the quantification of BA content and/or bacterial BA production in food samples $[31,73,74]$. When utilized in conjunction, the complementary methods, that is, HPLC and RT-qPCR, sufficiently allow for the quantitative analysis of both the BA content and tyramine-producing bacteria (including enterococci) in food products [24,31]. In the present study, the results derived from both techniques indicated that the fermentation of Cheonggukjang at high temperatures results in increased $t d c$ gene expression and tyramine production. Therefore, low-temperature fermentation appears to be necessary to minimize both $t d c$ gene expression and tyramine production by Enterococcus spp. and thereby ensure the safety of fermented soybean products.
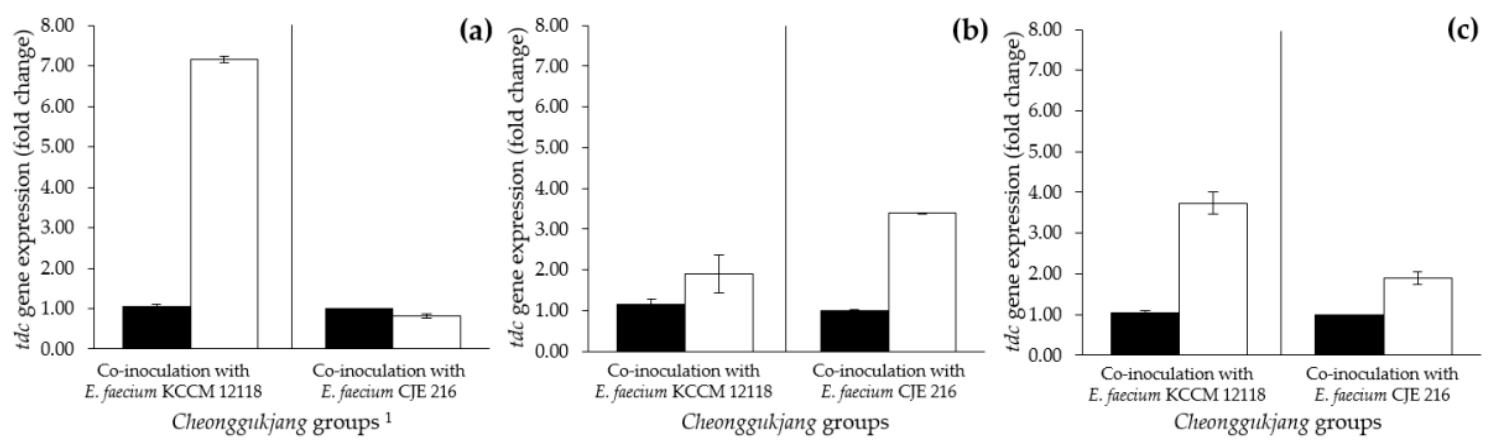

Figure 6. Effect of fermentation temperature on $t d c$ expression by E. faecium strains in Cheonggukjang on (a) day $1,(\mathbf{b})$ day 2 , and (c) day 3 of fermentation. : $37^{\circ} \mathrm{C}, \square: 45^{\circ} \mathrm{C} .{ }^{1}$ Cheonggukjang groups were co-inoculated with B. subtilis (KCTC 3135) and E. faecium (KCCM 12118 or CJE 216) strains. The expression levels observed in groups fermented at $45^{\circ} \mathrm{C}$ were normalized to those detected in the corresponding groups fermented at $37^{\circ} \mathrm{C}$. Expression of $t d c$ gene was not detected in Cheonggukjang fermented at $25^{\circ} \mathrm{C}$. Error bars indicate standard deviations calculated from duplicate experiments.

\section{Conclusions}

The current study assessed the safety risk of tyramine in Cheonggukjang, diagnosed the microbial causative agent (i.e., E. faecium) responsible for high tyramine levels, and evaluated the impact of fermentation temperature on enterococcal growth (as well as acid production and $t d c$ gene expression) and tyramine production. Of the retail Cheonggukjang examined, half of the products contained tyramine content that exceeded the recommended limit for safe consumption by up to a factor of approximately 14. E. faecium strains isolated from the retail Cheonggukjang products were highly capable of producing tyramine in assay media, which indicated that the species is principally, or at least partly, responsible for tyramine accumulation in the food.

During in situ fermentation at different temperatures, the tyramine content of Cheonggukjang groups co-inoculated with B. subtilis (used as an inoculant to ferment soybeans) and E. faecium (either isolated in this study or designated previously as the type strain) strains was highest at $45^{\circ} \mathrm{C}$, followed by $37^{\circ} \mathrm{C}$ and $25^{\circ} \mathrm{C}$. On the other hand, the control group inoculated with only B. subtilis strain (without any E. faecium inoculants) had the lowest tyramine content at all fermentation temperatures, which supported the notion that E. faecium may be a key producer of tyramine in Cheonggukjang. Another implication of the results was that a lower fermentation temperature leads to a lower tyramine content below the recommended limit in Cheonggukjang, even though the tyramine content continually increases during fermentation. Therefore, low temperatures and a short fermentation duration may reduce the accumulation of tyramine caused by E. faecium growth in Cheonggukjang, thereby reducing the safety risks associated with consuming food with high BA concentrations. 
Author Contributions: Conceptualization, Y.K.P. and J.-H.M.; Investigation, Y.K.P., Y.H.J., J.-H.L., B.Y.B., and J.L.; Formal analysis, J.L.; Writing—original draft, Y.K.P.; Writing—review and editing, Y.K.P., Y.H.J., K.C.J., and J.-H.M.; Supervision: J.-H.M. All authors have read and agreed to the published version of the manuscript.

Funding: This work was supported by the National Research Foundation of Korea (NRF) grant funded by the Korea government (MSIT) (no. 2020R1I1A3052118).

Acknowledgments: The authors thank Jae Hoan Lee and Alixander Mattay Pawluk of Department of Food and Biotechnology at Korea University for technical assistance and English editing, respectively.

Conflicts of Interest: The authors declare no conflict of interest.

\section{References}

1. Jang, C.H.; Lim, J.K.; Kim, J.H.; Park, C.S.; Kwon, D.Y.; Kim, Y.-S.; Shin, D.H.; Kim, J.-S. Change of isoflavone content during manufacturing of cheonggukjang, a traditional Korean fermented soyfood. Food Sci. Biotechnol. 2006, 15, 643-646.

2. Kim, K.-J.; Ryu, M.-K.; Kim, S.-S. Chungkook-jang Koji fermentation with rice straw. Korean J. Food Sci. Technol. 1982, 14, 301-308.

3. Hong, S.W.; Kim, J.Y.; Lee, B.K.; Chung, K.S. The bacterial biological response modifier enriched Chungkookjang fermentation. Korean J. Food Sci. Technol. 2006, 38, 548-553.

4. Lee, J.-O.; Ha, S.-D.; Kim, A.-J.; Yuh, C.-S.; Bang, I.-S.; Park, S.-H. Industrial application and physiological functions of Chongkukjang. Food Sci. Ind. 2005, 38, 69-78.

5. Hwang, J.-S.; Kim, S.-J.; Kim, H.-B. Antioxidant and blood-pressure reduction effects of fermented soybean, Chungkookjang. Korean J. Microbiol. 2009, 45, 54-57.

6. Askar, A.; Treptow, H. Biogene Amine in Lebensmitteln: Vorkommen, Bedeutung und Bestimmung, 1st ed.; Eugen Ulmer: Stuttgart, Germany, 1986; pp. 21-74.

7. Silla Santos, M.H. Biogenic amines: Their importance in foods. Int. J. Food Microbiol. 1996, $29,213-231$. [CrossRef]

8. Shalaby, A.R. Significance of biogenic amines to food safety and human health. Food Res. Int. 1996, 29, 675-690. [CrossRef]

9. Ladero, V.; Calles-Enriquez, M.; Fernández, M.; Alvarez, M.A. Toxicological effects of dietary biogenic amines. Curr. Nutr. Food Sci. 2010, 6, 145-156. [CrossRef]

10. EFSA Panel on Biological Hazards (BIOHAZ). Scientific opinion on risk based control of biogenic amine formation in fermented foods. EFSA J. 2011, 9, 2393. [CrossRef]

11. Taylor, S.L.; Eitnmiller, R.R. Histamine food poisoning: Toxicology and clinical aspects. Crit. Rev. Toxicol. 1986, 17, 91-128. [CrossRef]

12. Kovacova-Hanuskova, E.; Buday, T.; Gavliakova, S.; Plevkova, J. Histamine, histamine intoxication and intolerance. Allergol. Immunopathol. 2015, 43, 498-506. [CrossRef] [PubMed]

13. Maintz, L.; Novak, N. Histamine and histamine intolerance. Am. J. Clin. Nutr. 2007, 85, 1185-1196. [CrossRef] [PubMed]

14. Smith, T.A. Amines in food. Food Chem. 1981, 6, 169-200. [CrossRef]

15. Stratton, J.E.; Hutkins, R.W.; Taylor, S.L. Biogenic amines in cheese and other fermented foods: A review. J. Food Prot. 1991, 54, 460-470. [CrossRef]

16. Linares, D.M.; Martín, M.; Ladero, V.; Alvarez, M.A.; Fernández, M. Biogenic amines in dairy products. Crit. Rev. Food Sci. Nutr. 2011, 51, 691-703. [CrossRef]

17. Schirone, M.; Tofalo, T.; Fasoli, G.; Perpetuini, G.; Corsetti, A.; Manetta, A.C.; Ciarrocchi, A.; Suzzi, G. High content of biogenic amines in Pecorino cheeses. Food Microbiol. 2013, 34, 137-144. [CrossRef]

18. Ko, Y.-J.; Son, Y.-H.; Kim, E.-J.; Seol, H.-G.; Lee, G.-R.; Kim, D.-H.; Ryu, C.-H. Quality properties of commercial Chungkukjang in Korea. J. Agric. Life Sci. 2012, 46, 177-187.

19. Jeon, A.R.; Lee, J.H.; Mah, J.-H. Biogenic amine formation and bacterial contribution in Cheonggukjang, a Korean traditional fermented soybean food. LWT Food Sci. Technol. 2018, 92, 282-289. [CrossRef]

20. Seo, M.-J.; Lee, C.-D.; Lee, J.-N.; Yang, H.-J.; Jeong, D.-Y.; Lee, G.-H. Analysis of biogenic amines and inorganic elements in Cheonggukjang. Korean J. Food Preserv. 2019, 26, 101-108. [CrossRef]

21. Ten Brink, B.; Damink, C.; Joosten, H.M.L.J.; Huis in 't Veld, J.H.J. Occurrence and formation of biologically active amines in foods. Int. J. Food Microbiol. 1990, 11, 73-84. [CrossRef] 
22. Ibe, A.; Nishima, T.; Kasai, N. Bacteriological properties of and amine-production conditions for tyramine-and histamine-producing bacterial strains isolated from soybean paste (miso) starting materials. Jpn. J. Toxicol. Environ. Health 1992, 38, 403-409. [CrossRef]

23. Torriani, S.; Gatto, V.; Sembeni, S.; Tofalo, R.; Suzzi, G.; Belletti, N.; Gardini, F.; Bover-Cid, S. Rapid detection and quantification of tyrosine decarboxylase gene $(t d c)$ and its expression in gram-positive bacteria associated with fermented foods using PCR-based methods. J. Food Prot. 2008, 71, 93-101. [CrossRef] [PubMed]

24. Ladero, V.; Fernández, M.; Cuesta, I.; Alvarez, M.A. Quantitative detection and identification of tyramine-producing enterococci and lactobacilli in cheese by multiplex qPCR. Food Microbiol. 2010, 27, 933-939. [CrossRef] [PubMed]

25. Kang, T.-M.; Park, J.-H. Isolation and antibiotic susceptibility of Enterococcus spp. from fermented soy paste. J. Korean Soc. Food Sci. Nutr. 2012, 41, 714-720. [CrossRef]

26. Kang, H.-R.; Lee, Y.-L.; Hwang, H.-J. Potential for application as a starter culture of tyramine-reducing strain. J. Korean Soc. Food Sci. Nutr. 2017, 46, 1561-1567. [CrossRef]

27. Svec, P.; Devriese, L.A. Enterococcus. In Bergey's Manual of Systematics of Archaea and Bacteria, 2nd ed.; De Vos, P., Garrity, G.M., Jones, D., Krieg, N.R., Ludwig, W., Rainey, F.A., Schleifer, K.-H., Whitman, W.B., Eds.; Springer: New York, NY, USA, 2015; Volume 3, pp. 594-607.

28. Food Information Statistics System. Available online: http://www.atfis.or.kr/article/M001050000/view.do? articleId=2452\&page $=5 \&$ searchKey=\&searchString $=\&$ searchCategory $=($ accessed on 29 May 2020).

29. Kim, I.-J.; Kim, H.-K.; Chung, J.-H.; Jeong, Y.-K.; Ryu, C.-H. Study of functional Chungkukjang contain fibrinolytic enzyme. Korean J. Life Sci. 2002, 12, 357-362.

30. Lee, N.-R.; Go, T.-H.; Lee, S.-M.; Hong, C.-O.; Park, K.-M.; Park, G.-T.; Hwang, D.-Y.; Son, H.-J. Characteristics of Chungkookjang prepared by Bacillus amyloliquefaciens with different soybeans and fermentation temperatures. Korean J. Microbiol. 2013, 49, 71-77. [CrossRef]

31. Bhardwaj, A.; Gupta, H.; Iyer, R.; Kumar, N.; Malik, R.K. Tyramine-producing enterococci are equally detected on tyramine production medium, by quantification of tyramine by HPLC, or by $t d c$ gene-targeted PCR. Dairy Sci. Technol. 2009, 89, 601-611. [CrossRef]

32. AOAC. Official Methods of Analysis of AOAC International, 18th ed.; AOAC International: Gaithersburg, MD, USA, 2005.

33. ISO 7218:2007. Microbiology of Food and Animal Feeding Stuffs-General Requirements and Guidance for Microbiological Examinations; ISO: Geneva, Switzerland, 2007.

34. Mareková, M.; Lauková, A.; DeVuyst, L.; Skaugen, M.; Nes, I.F. Partial characterization of bacteriocins produced by environmental strain Enterococcus faecium EK13. J. Appl. Microbiol. 2003, 94, 523-530. [CrossRef]

35. Ryu, M.S.; Yang, H.-J.; Kim, J.W.; Jeong, S.-J.; Jeong, S.-Y.; Eom, J.-S.; Jeong, D.-Y. Potential probiotics activity of Bacillus spp. from traditional soybean pastes and fermentation characteristics of Cheonggukjang. Korean J. Food Preserv. 2017, 24, 1168-1179. [CrossRef]

36. Lee, J.S.; Lee, M.H.; Kim, J.M. Changes in quality characteristics of cheonggukjang added with quinoa during fermentation period. Korean J. Food Nutr. 2018, 31, 24-32.

37. National Institute of Agricultural Sciences. Available online: https://koreanfood.rda.go.kr:2360/eng/ fctFoodSrchEng/engMain (accessed on 7 May 2020).

38. Ben-Gigirey, B.; Vieites Baptista De Sousa, J.M.; Villa, T.G.; Barros-Velazquez, J. Changes in biogenic amines and microbiological analysis in albacore (Thunnus alalunga) muscle during frozen storage. J. Food Prot. 1998, 61, 608-615. [CrossRef] [PubMed]

39. Eerola, S.; Hinkkanen, R.; Lindfors, E.; Hirvi, T. Liquid chromatographic determination of biogenic amines in dry sausages. J. AOAC Int. 1993, 76, 575-577. [CrossRef]

40. Ben-Gigirey, B.; Vieites Baptista De Sousa, J.M.; Villa, T.G.; Barros-Velazquez, J. Histamine and cadaverine production by bacteria isolated from fresh and frozen albacore (Thunnus alalunga). J. Food Prot. 1999, 62, 933-939. [CrossRef] [PubMed]

41. Marcobal, Á.; Martín-Álvarez, P.J.; Moreno-Arribas, M.V.; Muñoz, R. A multifactorial design for studying factors influencing growth and tyramine production of the lactic acid bacteria Lactobacillus brevis CECT 4669 and Enterococcus faecium BIFI-58. Res. Microbiol. 2006, 157, 417-424. [CrossRef] [PubMed]

42. Yoon, H.; Park, J.H.; Choi, A.; Hwang, H.-J.; Mah, J.-H. Validation of an HPLC analytical method for determination of biogenic amines in agricultural products and monitoring of biogenic amines in Korean fermented agricultural products. Toxicol. Res. 2015, 31, 299-305. [CrossRef] 
43. Kang, H.-R.; Kim, H.-S.; Mah, J.-H.; Kim, Y.-W.; Hwang, H.-J. Tyramine reduction by tyrosine decarboxylase inhibitor in Enterococcus faecium for tyramine controlled cheonggukjang. Food Sci. Biotechnol. 2018, 27, 87-93. [CrossRef]

44. Top, J.; Paganelli, F.L.; Zhang, X.; van Schaik, W.; Leavis, H.L.; Van Luit-Asbroek, M.; van der Poll, T.; Leendertse, M.; Bonten, M.J.M.; Willems, R.J.L. The Enterococcus faecium enterococcal biofilm regulator, EbrB, regulates the esp operon and is implicated in biofilm formation and intestinal colonization. PLOS ONE 2013, 8, e65224. [CrossRef]

45. Lee, E.S.; Kim, Y.S.; Ryu, M.S.; Jeong, D.Y.; Uhm, T.B.; Cho, S.H. Characterization of Bacillus licheniformis SCK A08 with antagonistic property against Bacillus cereus and degrading capacity of biogenic amines. J. Food Hyg. Saf. 2014, 29, 40-46. [CrossRef]

46. Yoo, S.-M.; Choe, J.-S.; Park, H.-J.; Hong, S.-P.; Chang, C.-M.; Kim, J.-S. Physicochemical properties of traditional Chonggugjang produced in different regions. Appl. Biol. Chem. 1998, 41, 377-383.

47. Kim, J.-W.; Kim, Y.-S.; Jeong, P.-H.; Kim, H.-E.; Shin, D.-H. Physicochemical characteristics of traditional fermented soybean products manufactured in folk villages of Sunchang region. J. Food Hyg. Saf. 2006, 21, 223-230.

48. Jeong, W.J.; Lee, A.R.; Chun, J.; Cha, J.; Song, Y.-S.; Kim, J.H. Properties of cheonggukjang fermented with Bacillus strains with high fibrinolytic activities. J. Food Sci. Nutr. 2009, 14, 252-259. [CrossRef]

49. Kang, S.J.; Kim, S.S.; Chung, H.Y. Comparison of physicochemical characteristics and consumer perception of Cheongkukjang. J. Korean Soc. Food Sci. Nutr. 2014, 43, 1104-1111. [CrossRef]

50. Oh, S.-J.; Mah, J.-H.; Kim, J.-H.; Kim, Y.-W.; Hwang, H.-J. Reduction of tyramine by addition of Schizandra chinensis Baillon in Cheonggukjang. J. Med. Food 2012, 15, 1109-1115. [CrossRef] [PubMed]

51. International Commission on Microbiological Specifications for Foods International Association of Microbiological Societies. Reduced water activity. In Microbial Ecology of Foods, 1st ed.; Silliker, J.H., Elliot, R.P., Baird-Parker, A.C., Bryan, F.L., Christian, J.H.B., Clark, D.S., Olson, J.C., Roberts, T.A., Eds.; Academic Press: New York, NY, USA, 1980; Volume 1, pp. 70-91.

52. Li, L.; Ruan, L.; Ji, A.; Wen, Z.; Chen, S.; Wang, L.; Wei, X. Biogenic amines analysis and microbial contribution in traditional fermented food of Douchi. Sci. Rep. 2018, 8, 1-10. [CrossRef] [PubMed]

53. Takebe, Y.; Takizaki, M.; Tanaka, H.; Ohta, H.; Niidome, T.; Morimura, S. Evaluation of the biogenic amine-production ability of lactic acid bacteria isolated from tofu-misozuke. Food Sci. Technol. Res. 2016, 22, 673-678. [CrossRef]

54. Giraffa, G. Enterococci from foods. FEMS Microbiol. Rev. 2002, 26, 163-171. [CrossRef]

55. Giraffa, G.; Carminati, D.; Neviani, E. Enterococci isolated from dairy products: A review of risks and potential technological use. J. Food Prot. 1997, 60, 732-738. [CrossRef]

56. Bandara, N.; Chung, S.-J.; Jeong, D.-Y.; Kim, K.-P. The use of the pathogen-specific bacteriophage BCP8-2 to develop a rice straw-derived Bacillus cereus-free starter culture. Korean J. Food Sci. Technol. 2014, 46, 115-120. [CrossRef]

57. Heu, J.-S.; Lee, I.-J.; Yoon, M.-H.; Choi, W.-Y. Adhesive microbial populations of rice straws and their effects on Chungkukjang fermentation. Korean J. Agric. Sci. 1999, 26, 77-83.

58. Seok, Y.-R.; Kim, Y.-H.; Kim, S.; Woo, H.-S.; Kim, T.-W.; Lee, S.-H.; Choi, C. Change of protein and amino acid composition during Chungkook-Jang fermentation using Bacillus licheniformis CN-115. Korean J. Agic. Sci. 1994, 37, 65-71.

59. Cho, T.-Y.; Han, G.-H.; Bahn, K.-N.; Son, Y.-W.; Jang, M.-R.; Lee, C.-H.; Kim, S.-H.; Kim, D.-B.; Kim, S.-B. Evaluation of biogenic amines in Korean commercial fermented foods. Korean J. Food Sci. Technol. 2006, 38, 730-737.

60. Han, G.-H.; Cho, T.-Y.; Yoo, M.-S.; Kim, C.-S.; Kim, J.-M.; Kim, H.-A.; Kim, M.-O.; Kim, S.-C.; Lee, S.-A.; Ko, Y.-S.; et al. Biogenic amines formation and content in fermented soybean paste (cheonggukjang). Korean J. Food Sci. Technol. 2007, 39, 541-545.

61. Rice, S.L.; Eitenmiller, R.R.; Koehler, P.E. Biologically active amines in food: A review. J. Milk Food Technol. 1976, 39, 353-358. [CrossRef]

62. Rodriguez-Jerez, J.J.; Giaccone, V.; Colavita, G.; Parisi, E. Bacillus macerans-A new potent histamine producing micro-organism isolated from Italian cheese. Food Microbiol. 1994, 11, 409-415. [CrossRef] 
63. Novella-Rodríguez, S.; Veciana-Nogues, M.T.; Roig-Sagues, A.X.; Trujillo-Mesa, A.J.; Vidal-Carou, M.C. Evaluation of biogenic amines and microbial counts throughout the ripening of goat cheeses from pasteurized and raw milk. J. Dairy Res. 2004, 71, 245-252. [CrossRef] [PubMed]

64. Marcobal, A.; de las Rivas, B.; Moreno-Arribas, M.V.; Munoz, R. Evidence for horizontal gene transfer as origin of putrescine production in Oenococcus oeni RM83. Appl. Environ. Microbiol. 2006, 72, 7954-7958. [CrossRef] [PubMed]

65. Condori, J.; Nopo-Olazabal, C.; Medrano, G.; Medina-Bolivar, F. Selection of reference genes for qPCR in hairy root cultures of peanut. BMC Res. Notes 2011, 4, 392. [CrossRef] [PubMed]

66. Loizzo, M.R.; Menichini, F.; Picci, N.; Puoci, F.; Spizzirri, U.G.; Restuccia, D. Technological aspects and analytical determination of biogenic amines in cheese. Trends Food Sci. Technol. 2013, 30, 38-55. [CrossRef]

67. Cosansu, S. Determination of biogenic amines in a fermented beverage, boza. J. Food Agric. Environ. 2009, 7, 54-58.

68. Mann, S.-Y.; Kim, E.-A.; Lee, G.-Y.; Kim, R.-U.; Hwang, D.-Y.; Son, H.-J.; Kim, D.-S. Isolation and identification of GABA-producing microorganism from Chungkookjang. J. Life Sci. 2013, 23, 102-109. [CrossRef]

69. Morandi, S.; Brasca, M.; Alfieri, P.; Lodi, R.; Tamburini, A. Influence of $\mathrm{pH}$ and temperature on the growth of Enterococcus faecium and Enterococcus faecalis. Le Lait 2005, 85, 181-192. [CrossRef]

70. Van den Berghe, E.; De Winter, T.; De Vuyst, L. Enterocin A production by Enterococcus faecium FAIR-E 406 is characterised by a temperature-and $\mathrm{pH}$-dependent switch-off mechanism when growth is limited due to nutrient depletion. Int. J. Food Microbiol. 2006, 107, 159-170. [CrossRef] [PubMed]

71. Kalhotka, L.; Manga, I.; Přichystalová, J.; Hůlová, M.; Vyletělová, M.; Šustová, K. Decarboxylase activity test of the genus Enterococcus isolated from goat milk and cheese. Acta Vet. BRNO 2012, 81, 145-151. [CrossRef]

72. Glanemann, C.; Loos, A.; Gorret, N.; Willis, L.B.; O'brien, X.M.; Lessard, P.A.; Sinskey, A.J. Disparity between changes in mRNA abundance and enzyme activity in Corynebacterium glutamicum: Implications for DNA microarray analysis. Appl. Microbiol. Biotechnol. 2003, 61, 61-68. [CrossRef] [PubMed]

73. Ladero, V.; Linares, D.M.; Fernández, M.; Alvarez, M.A. Real time quantitative PCR detection of histamine-producing lactic acid bacteria in cheese: Relation with histamine content. Food Res. Int. 2008, 41, 1015-1019. [CrossRef]

74. Spano, G.; Russo, P.; Lonvaud-Funel, A.; Lucas, P.; Alexandre, H.; Grandvalet, C.; Coton, E.; Coton, M.; Barnavon, L.; Bach, B.; et al. Biogenic amines in fermented foods. Eur. J. Clin. Nutr. 2010, 64, S95-S100. [CrossRef]

(C) 2020 by the authors. Licensee MDPI, Basel, Switzerland. This article is an open access article distributed under the terms and conditions of the Creative Commons Attribution (CC BY) license (http://creativecommons.org/licenses/by/4.0/). 